\title{
Pleomorphic Adenoma with Exuberant Squamous Metaplasia and Keratin Cysts Mimicking Squamous Cell Carcinoma in Minor Salivary Gland
}

\author{
Sharon Lim ${ }^{1}$, Inju Cho ${ }^{1}$, Jun-Hee Park ${ }^{2}$, Sung-Chul Lim ${ }^{1}$ \\ ${ }^{1}$ Department of Pathology, Chosun University College of Medicine, Gwangju, South Korea; ${ }^{2}$ Department of Otorhinolaryngology, \\ Chosun University College of Medicine, Gwangju, South Korea. \\ Email: sclim@chosun.ac.kr
}

Received April $4^{\text {th }}, 2013$; revised May 24 ${ }^{\text {th }}, 2013$; accepted June $25^{\text {th }}, 2013$

Copyright (C) 2013 Sharon Lim et al. This is an open access article distributed under the Creative Commons Attribution License, which permits unrestricted use, distribution, and reproduction in any medium, provided the original work is properly cited.

\begin{abstract}
Salivary gland tumors, the second most common neoplasm of the mouth after squamous cell carcinoma, account for a significant proportion of tumors of the oral and perioral regions. An unusual case of adenoma presented as a solitary intraoral palatine mass in a 32-year-old woman is reported here. The tumor was interpreted as an unusual pleomorphic adenoma because of the presence of exuberant squamous metaplasia, clinically mimicking squamous cell carcinoma. Moreover, the presence of cystic structures filled with keratinized material was also salient feature. Pleomorphic adenomas may occasionally display focal squamous metaplastic changes; when extensive, it presents the potential for misinterpretation of the histology as indicative of well-differentiated squamous cell carcinoma.
\end{abstract}

Keywords: Pleomorphic Adenoma; Squamous Metaplasia; Keratin Cyst; Squamous Cell Carcinoma; Salivary Gland

\section{Introduction}

Histological diversity is the hallmark of pleomorphic adenoma (PA). Its histological patterns may vary considerably among different parts of the same tumor [1]. Not only does the proportion between epithelial and chondromyxoid stroma vary, but some metaplastic variations also occur in the epithelial and stromal components. Thus, morphological diversity may often cause a diagnostic problem in surgical pathology due to the limited or selective sampling [2,3].

Squamous metaplasia can be experimentally induced in the salivary gland following arterial ligation $[4,5]$, radiation [6], and carcinogen exposure [5,7]. Focal squamous metaplasia may be found in about $25 \%$ of the PA [8], while florid squamous metaplasia is known to occur rarely [9]. Adnexal differentiation in the form of keratin-filled cysts is also evident in salivary gland $[9,10]$.

Exuberant squamous metaplastic changes in PA present the potential for its misinterpretation as a squamous cell carcinoma. Squamous cell carcinoma as a collision tumor or carcinoma ex PA must be considered in the differential diagnosis. Our study emphasizes the need for a cautious and systematic approach in the histopathologic interpretation of the squamous component to avoid misdiagnosis and subsequent overtreatment of PA.

PA with exuberant squamous metaplasia and keratinfilled cysts may cause diagnostic confusion that stresses the need for a guarded approach while interpreting such lesions. In this study, we present an unusual case of PA with exuberant squamous metaplasia and keratin cysts formations in a minor salivary gland, and discuss its pathogenesis, potential diagnostic pitfalls, proliferative activity, and cytokeratin expression.

\section{Case Report}

A 32-year-old woman presented to the hospital under the impression of palatine tumor for further evaluation and treatment. She had a three-month history of painless mass on the right side of the soft palate. No history of surgery, trauma, or infection was evidenced. On physical examination, a soft tissue mass in the soft palate was palpated (Figure 1). Radiographic examination showed a relatively well-defined high signal intensity mass with internal cystic component in the right side of the soft palate (Figure 2). Bony erosion in the adjacent region of right maxilla was identified. There was no visible cervi- 


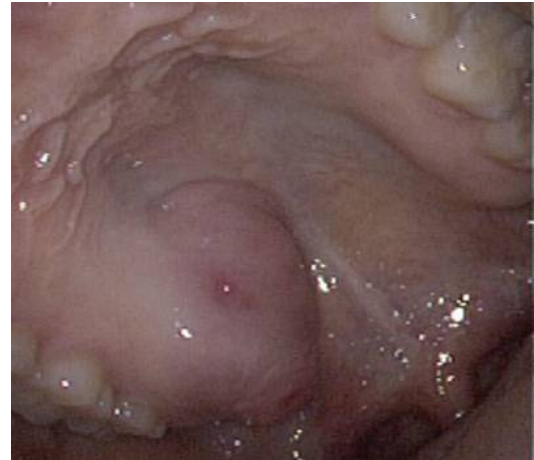

Figure 1. Gross finding. Intraoral palatine mass was identified in the right side of the soft palate.

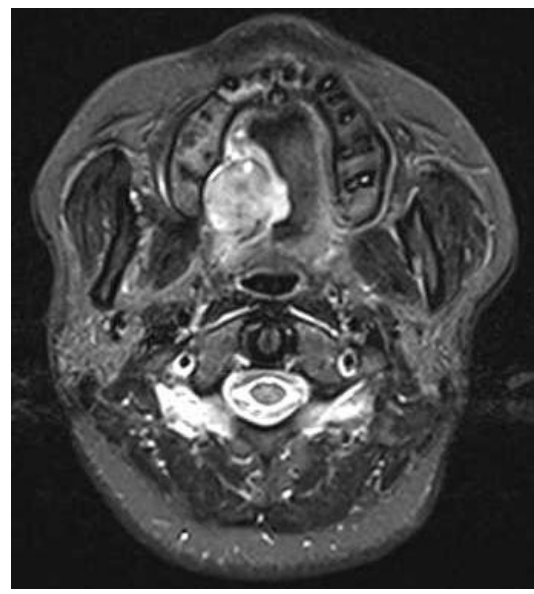

Figure 2. CT scan showed a relatively well-defined high signal intensity mass with internal cystic component.

cal lymphadenopathy. Histopathologic diagnosis on a punch biopsy was done as PA arising in the minor salivary gland. Complete mass excision was undertaken 16 days after biopsy. The mass was whitish yellow and measured $3.5 \times 3.0 \times 2.0 \mathrm{~cm}$. Histopathologic findings showed a relatively well-circumscribed typical benign mixed tumor composed of both epithelial and myoepithelial cells in a myxoid mesenchymal background. More than $45 \%$ of the epithelial element in the tumor was composed of sheets of squamous cells with superficial and deep-seated keratin cysts. The epithelial component of the tumor formed solid sheets, nests, finger-like projections or cords, and ductal structures (Figure 3).

A double layer of cells lined the ductal component. Outer cells showed positive immunoreactivity for p63, S-100 protein, and high-molecular weight (Hmw) cytokeratin (CK), but negative for CK7 and CK19. Inner cells showed positive immunoreactivity for CK7 and CK19, but negative for p63, S-100 protein, and Hmw CK.

Epithelial component not having lumen composed of squamous cells with distinct intercellular junctions or

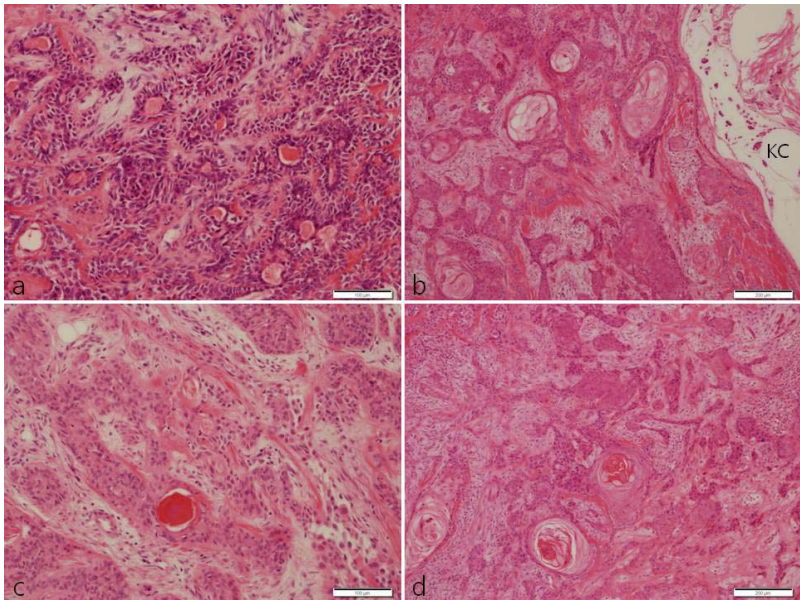

Figure 3. Histopathologic findings. (a) Typical findings of benign mixed tumor composed of both epithelial and myoepithelial cells in a myxoid mesenchymal background; (b) Cords or trabecular arrangement of pseudoinfiltrative squamous cells around the keratin cyst (KC) mimick welldifferentiated squamous cell carcinoma; (c) Squamoid area consists of vague lumens, keratin lamellae and peripheral myoepithelial cells; (d) Remote area from the keratin cyst showing squamous cell differentiation. Scale bars measure $100 \mu \mathrm{m}$ (a) and (c) and $200 \mu \mathrm{m}$ (b) and (d). Hematoxylin \& Eosin staining.

keratin pearls, squamoid cells, and keratin cyst containing keratotic lamellae. These cells showed focal immunoreactivity for CK7, CK19, Hmw CK, or S-100 protein. Cells in the basal layer exhibited positive p63 immunoreactivity (Figure 4).

Cellular proliferation indices, calculated as the percentage of Ki-67 positive tumor cells, were low either in the typical PA area $(1.6 \%)$ or in the squamous area with keratin cyst (1.8\% - 2.6\%) (Figure 5).

According to the morphological findings and clinical history, in addition to PA with exuberant squamous metaplasia, squamous cell carcinoma and reactive squamous hyperplasia must also be considered in the differential diagnosis. But, immunohistochemical profiles support the diagnosis of PA with exuberant squamous metaplasia. The postoperative course was uneventful, and no evidence of disease recurrence was seen 10 months after surgery.

\section{Discussion}

Presence of squamoid or frankly squamous epithelia is a common feature of a number of reactive or neoplastic conditions of the salivary glands. Depending on the reactive conditions, chronic sialadenitis [11], radiation change of salivary glands [6], and necrotizing sialometaplasia $[12,13]$ can be associated with the squamous metaplasia, while neoplastic conditions associate these cells with 


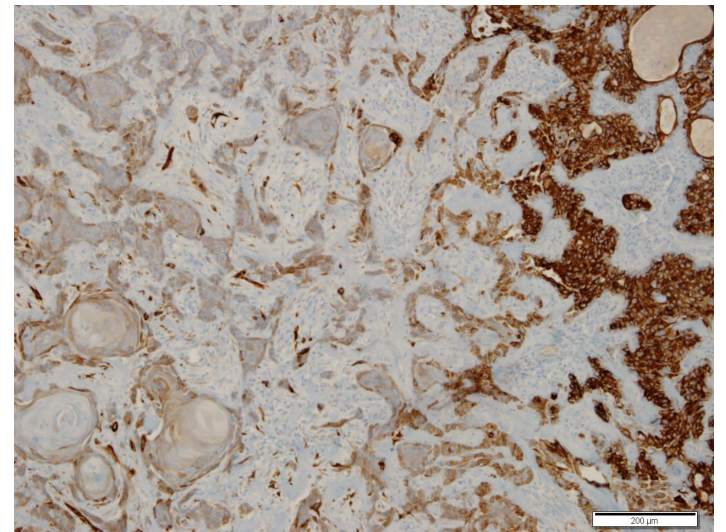

Figure 4. Immunohistochemical staining for cytokeratin 7. Focal immunoreactivity was identified in the squamous area, but diffuse strong immunoreactivity was noted in the area of ductal differentiation (right). Scale bar measures $200 \mu \mathrm{m}$. ABC method counterstained by hematoxylin.

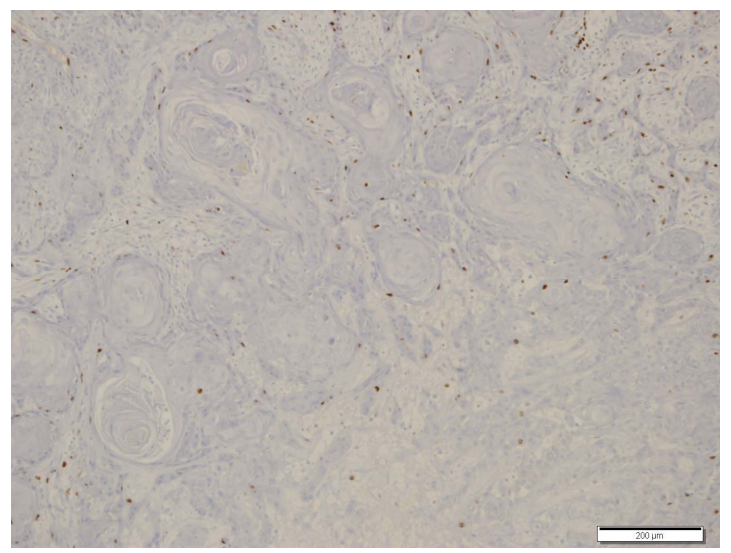

Figure 5. Cellular proliferation index. Immunostaining for Ki-67 showed low index ( $<5 \%)$. Scale bar measures $200 \mu \mathrm{m}$. ABC method counterstained by hematoxylin.

mucoepidermoid carcinoma, PA, basal cell adenoma, and Warthin's tumor [14,15].

PA is characterized by great histologic diversity; however, PA with exuberant squamous metaplasia is uncommon and can be diagnostically challenging [1-3,9]. Focal squamous metaplasia in PA can be related to ischemia [16], and may be found in about $25 \%$ of the PA [8]. The present case showed exuberant squamous proliferation in the deep as well as in the superficial regions. Thus, squamous cell carcinoma should always be considered in the differential diagnosis. A collision tumor consisting of squamous cell carcinoma arising in the overlying squamous mucosa epithelia of PA and squamous cell carcinoma ex PA are possible. Moreover, the present case had a history of previous biopsy 16 days ago. Hence, exuberant reactive squamous hyperplasia should be ruled out before clinical diagnosis. The previous biopsy showed intact overlying squamous epithelium with- out atypia. Therefore, it is very important whether the squamous component of the PA is malignant or not. Squamous component also contained areas that showed mild cellular atypia characterized by some prominent nucleoli and hyperchromasia, but the proliferation indices (Ki-67 labeling indices) were not high $(<5 \%)$ in all of the squamous areas. Benign nature of this tumor is identified by the absence of significant cellular atypia, metastasis and tumor necrosis, and low cellular proliferative index.

The squamous epithelium lining the keratin cyst formations was homogenously positive for Hmw CK. However, some cells expressed low-molecular weight (Lmw) CK (CK7 and CK19) and p63. The pattern of CK expression suggests that the cells that express Hmw CK have undergone squamous metaplasia, but those expressing Lmw CK and p63 have not yet undergone squamous metaplasia. These morphologically similar squamoid cells are metaplastic squamous cells and ductal epithelial cells showing squamoid features depending on the immunohistochemical and morphologic profiles, respectively. If the squamoid areas were squamous cell carcinoma or reactive squamous hyperplasia, Lmw CK and p63 were not expressed in the present case. Therefore, squamoid areas forming keratin pearls or distinct intercellular junctions and keratin cysts containing keratin lamellae are areas of metaplasia of the PA.

Some areas of the squamous component showed squamous epithelium-lined keratin cysts. Previous reports $[8,17]$ have designated the similar lesion as adnexal differentiation because of the histologic patterns mimicking skin appendages. The reported adnexal differentiation was mainly composed of squamous cells, devoid of glandular differentiation including duct-like formations and myoepithelial cells, which are present in our demonstrated case by means of morphological and immunohistochemical aspects. The squamous metaplasia exhibited keratinized cysts containing keratin lamellae and squamous cell islands forming keratin pearls or distinct intercellular junctions in some areas.

PAs, particularly of minor glands of palate, may contain large areas of squamous and mucinous metaplasia suspicious of squamous cell carcinoma or mucoepidermoid carcinoma. To prevent the misdiagnosis of PA with exuberant squamous metaplasia as squamous cell carcinoma, cautious and systematic approach in the histopathologic interpretation of the squamous component is needed.

\section{REFERENCES}

[1] C. Margaritescu, M. Raica, M. Florescu, C. Simionescu, M. Surpateanu, F. Jaubert and F. Bogdan, "The Ultrastructural Aspects of Neoplastic Myoepithelial Cell in 
Pleomorphic Adenomas of Salivary Glands,” Journal of Cellular and Molecular Medicine, Vol. 8, No. 3, 2004, pp. 369-381. doi:10.1111/j.1582-4934.2004.tb00326.x

[2] M. Batrani, M. Kaushal, A. K. Sen, R. Yadav and N. K. Chaturvedi, "Pleomorphic Adenoma with Squamous and Appendageal Metaplasia Mimicking Mucoepidermoid Carcinoma on Cytology," CytoJournal, Vol. 6, 2008, p. 5. doi:10.4103/1742-6413.45496

[3] V. C. Araujo, S. O. M. Souza, Y. R. Carvalho and N. S. Araujo, "Application of Immunohistochemistry to the Diagnosis of Salivary Gland Tumors," Applied Immunohistochemistry and Molecular Morphology, Vol. 8, No. 3, 2000, pp. 195-202. doi:10.1097/00022744-200009000-00005

[4] S. M. Standish and W. G. Shafer, "Serial Histologic Effects of Rat Submaxillary and Sublingual Salivary Gland Duct and Blood Vessel Ligation,” Journal of Dental Research, Vol. 36, No. 6, 1957, pp. 866-879. doi:10.1177/00220345570360060801

[5] A. Englander and E. Cataldo, "Experimental Carcinogenesis in Duct-Artery Ligated Rat Submandibular Gland,” Journal of Dental Research, Vol. 55, No. 2, 1976, pp. 229-234. doi:10.1177/00220345760550021101

[6] M. Friedman and J. W. Hall, "Radiation-Induced Squamous-Cell Metaplasia and Hyperplasia of the Normal Mucous Glands of the Oral Cavity,” Radiology, Vol. 55, No. 6, 1950, pp. 848-851.

[7] S. M. Standish, "Early Histologic Changes in Induced Tumors of the Submaxillary Salivary Glands of the Rat," American Journal of Pathology, Vol. 33, No. 4, 1957, pp. 671-689.

[8] G. Seifert, K. Donath and G. Jautzke, "Unusual Choristoma of the Parotid Gland in a Girl. A Possible Trichoadenoma," Virchows Archives, Vol. 434, No. 4, 1999, pp. 355-359. doi:10.1007/s004280050352

[9] E. F. Brachtel, B. Z. Pilch, U. Khettry, A. Zembowicz and W. C. Faquin, "Fine-Needle Aspiration Biopsy of a Cystic Pleomorphic Adenoma with Extensive Adnexa-Like Differentiation: Differential Diagnostic Pitfall with $\mathrm{Mu}-$ coepidermoid Carcinoma," Diagnostic Cytopathology, Vol. 28, No. 2, 2003, pp. 100-103. doi:10.1002/dc. 10240
[10] N. Siddaraju, P. Murugan, D. Basu and S. K. Verma, "Preoperative Cytodiagnosis of Cystic Pleomorphic Adenoma with Squamous Metaplasia and Cholesterol Crystals: A Case Report,” Acta Cytologica, Vol. 53, No. 1, 2009, pp. 101-104. doi:10.1159/000325093

[11] J. L. Jensen, F. V. Howell, G. M. Rick and R. W. Correll, "Minor Salivary Gland Calculi. A Clinicopathologic Study of Forty-Seven New Cases," Oral Surgery, Oral Medicine, and Oral Pathology, Vol. 47, No. 1, 1979, pp. 44-50. doi:10.1016/0030-4220(79)90100-2

[12] A. M. Abrams, R. J. Melrose and F. V. Howell, "Necrotizing Sialometaplasia: A Disease Simulating Malignancy," Cancer, Vol. 32, No. 1, 1973, pp. 130-135. doi:10.1002/1097-0142(197307)32:1<130::AID-CNCR28 20320118>3.0.CO;2-8

[13] R. Kruger and H. G. Dietrich, "Salivary Gland Infarction (Necrotizing Sialometaplasia)-Differential Diagnosis and Pathogenesis,” Pathologe, Vol. 3, No. 6, 1982, pp. 342 347.

[14] E. F. Brachtel, B. Z. Pilch, U. Khettry, A. Zembowicz and W. C. Faquin, "Fine-Needle Aspiration Biopsy of a Cystic Pleomorphic Adenoma with Extensive Adnexa-Like Differentiation: Differential Diagnostic Pitfall with Mucoepidermoid Carcinoma,” Diagnostic Cytopathology, Vol. 28, No. 2, 2003, pp. 100-103. doi:10.1002/dc.10240

[15] I. Paker, D. Yilmazer, A. T. Arikok, G. Saylam and S. Hucumenoglu, "Basal Cell Adenoma with Extensive Squamous Metaplasia and Cellular Atypia: A Case Report with Cytohistopathological Correlation and Review of the Literature," Diagnostic Cytopathology, Vol. 40, No. 1, 2012, pp. 48-55. doi:10.1002/dc.21584

[16] I. Dardick, M. T. Jeans, N. M. Sinnott, J. F. Wittkuhn, H. J. Kahn and R. Baumal, "Salivary Gland Components Involved in the Formation of Squamous Metaplasia," American Journal of Pathology, Vol. 119, No. 1, 1985, pp. 33-43.

[17] N. Siddaraju, P. Murugan, D. Basu and S. K. Verma, "Preoperative Cytodiagnosis of Cystic Pleomorphic Adenoma with Squamous Metaplasia and Cholesterol Crystals: A Case Report,” Acta Cytologica, Vol. 53, No. 1, 2009, pp. 101-104. doi:10.1159/000325093 